\title{
BMJ
}

\section{Five year prognosis in patients with angina identified in primary care: incident cohort study}

\author{
Brian S Buckley, Cochrane research fellow, ${ }^{1}$ Colin R Simpson, research fellow, ${ }^{2}$ David J McLernon, research \\ fellow, ${ }^{3}$ Andrew W Murphy, professor of general practice, ${ }^{4}$ Philip C Hannaford, NHS Grampian chair of primary \\ care and head of division of applied health sciences ${ }^{5}$
}

${ }^{1}$ Department of General Practice, National University of Ireland,

Galway, Ireland

${ }^{2}$ Centre of Academic Primary Care, University of Aberdeen Foresterhill Health Centre,

Aberdeen, Scotland

${ }^{3}$ Medical Statistics Team, Section of Population Health, University of Aberdeen, Polwarth Building, Foresterhill, Aberdeen, Scotland.

${ }^{4}$ National University of Ireland, Galway, Ireland

${ }^{5}$ University of Aberdeen, Foresterhill Health Centre, Aberdeen, Scotland

Correspondence to: B S Buckley bsbuckley@iolie

Cite this as: $B M J$ 2009;339:b3058 doi:10.1136/bmi.b3058

\section{ABSTRACT}

Objective To ascertain the risk of acute myocardial infarction, invasive cardiac procedures, and mortality among patients with newly diagnosed angina over five years.

Design Incident cohort study of patients with primary care data linked to secondary care and mortality data.

Setting 40 primary care practices in Scotland.

Participants 1785 patients with a diagnosis of angina as their first manifestation of ischaemic heart disease, 1 January 1998 to 31 December 2001.

Main outcome measures Adjusted hazard ratios for acute myocardial infarction, coronary artery bypass grafting, percutaneous transluminal coronary angioplasty, death from ischaemic heart disease, and all cause mortality, adjusted for demographics, lifestyle risk factors, and comorbidity at cohort entry.

Results Mean age was 62.3 (SD 11.3). Male sex was associated with an increased risk of acute myocardial infarction (hazard ratio 2.01, 95\% confidence interval 1.35 to 2.97 ), death from ischaemic heart disease (2.80, 1.73 to 4.53$)$, and all cause mortality $(1.82,1.33$ to 2.49$)$. Increasing age was associated with acute myocardial infarction (1.04, 1.02 to 1.06 , per year of age increase), death from ischaemic heart disease $(1.09,1.06$ to 1.11 , per year of age increase), and all cause mortality (1.09, 1.07 to 1.11 , per year of age increase). Smoking was associated with subsequent acute myocardial infarction (1.94, 1.31 to 2.89$)$, death from ischaemic heart disease $(2.12,1.32$ to 3.39$)$, and all cause mortality $(2.11,1.52$ to 2.95). Obesity was associated with death from ischaemic heart disease $(2.01,1.17$ to 3.45$)$ and all cause mortality $(2.20,1.52$ to 3.19$)$. Previous stroke was associated with all cause mortality $(1.78,1.13$ to 2.80$)$ and chronic kidney disease with death from ischaemic heart disease (5.72, 1.74 to 18.79 ). Men were more likely than women to have coronary artery bypass grafting or percutaneous transluminal coronary angioplasty after a diagnosis of angina; older people were less likely to receive percutaneous transluminal coronary angioplasty. Acute myocardial infarction after a diagnosis of angina was associated with an increased risk of death from ischaemic heart disease and all cause mortality (8.84 (5.31 to 14.71) and 4.23 (2.78 to 6.43), respectively). Neither of the invasive cardiac procedures significantly reduced the subsequent risk of all cause mortality.

Conclusions In this sample of people with incident angina from primary care, there were sex differences in survival and age and sex differences in the provision of revascularisation after a diagnosis. Acute myocardial infarction after a diagnosis of angina was strongly predictive of mortality. To minimise adverse outcomes, optimal preventive treatments should be used in patients with angina.

\section{INTRODUCTION}

In the United Kingdom, angina is common and is often the first manifestation of ischaemic heart disease. Recent prevalence estimates based on the Rose angina questionnaire suggest that $4.8 \%$ of men and $3.4 \%$ of women aged over 16 in England have the condition, ${ }^{1}$ while in Scotland angina diagnosed by a doctor is reported to occur in $6.6 \%$ and $5.6 \%$, respectively. ${ }^{2}$ Understanding the risk of acute myocardial infarction, invasive cardiac procedures, and death after a diagnosis of angina is important for patients and their clinicians, especially those working in primary care, where most cases of angina are first detected. Most previous studies of the prognostic importance of angina have examined populations identified from secondary or tertiary care settings. Descriptions of prognosis derived from such settings might be misleading in management of patients in primary care. The referral process might introduce important selection biases that could affect our understanding of the prognosis of people identified in primary care. Others have already shown that patients entered into hospital based trials of blood pressure control after stroke have important differences in age, sex, and blood pressure compared with patients managed in the community after their stroke. ${ }^{3}$ The Renfrew-Paisley epidemiological study offered valuable insights into prognosis among a population derived sample of people with possible angina as identified by the Rose angina questionnaire: compared with men, women had a reduced risk of death from any cardiovascular cause, ischaemic heart disease, or acute myocardial infarction and a reduced risk of admission to hospital 
for any of these indications. ${ }^{4}$ The cohort was of prevalent rather than incident cases, recruited only people aged 45-64 at entry, and included those with pre-existing angina and other ischaemic heart disease.

So far the few prognostic studies of angina in primary care are of limited value because they are comparatively old, included small numbers, or were of poor quality, leading researchers to comment that more studies are still needed..$^{5-7}$ We examined the risk of several cardiac outcomes (acute myocardial infarction, invasive cardiac procedures, and death) during the first five years after a first diagnosis of angina in a population identified from primary care in Scotland.

\section{METHODS}

\section{Sampling frame}

The sampling frame for the study was all patients registered with 40 practices in Scotland. The practices have been participating in the practice team information project operated by the information services division of the NHS in Scotland and contributing data to the primary care clinical informatics unit at the University of Aberdeen. ${ }^{8}$ In May 2007 the primary care patient data were linked with deprivation score (Scottish index of multiple deprivation ${ }^{9}$ ), secondary care data held on the Scottish morbidity record (SMR01) databases housed by the information services division, and cause of death data, which is collected by the general register office for Scotland (GROS) and routinely linked to the Scottish morbidity record by the information services division, to create a novel linked research database. The patients within the linked database are broadly representative of the Scottish population with respect to age, sex, and social deprivation. ${ }^{10}$

\section{Incident sample}

From the linked database we identified everyone with a diagnosis of angina pectoris (Read codes G311, G33 to G330z, G33z-G33zz, Gyu30) for the first time between 1 January 1998 and 31 December 2001. This was designated as the index episode. For as long as the identified patients were alive we checked each general practice electronic record for any record of ischaemic heart disease (Read code G3 to G330z, G33z to G3401, G342 to G366, G38 to G3z, Gyu3), atrial fibrillation (G573, G5730 to G573z, 212R), or heart failure (G58, G580, G5800 to G5803, G581, G5810, G582, G1yz1) before the date of the index episode. We also checked the secondary care information for each person to see whether there was a diagnosis of ischaemic heart disease (ICD-9 (international classification of diseases, ninth revision) codes 410 to 414 (1981-96) and ICD10 codes I20 to I22, I24 to I25, I42, I46, I50 (1997 onwards)) back to 1981, when reliable SMR01 records began. We excluded individuals with a relevant primary or secondary care diagnosis recorded before the index episode. Those without such a record were deemed to have experienced an incident (first ever) episode of angina on the index date.

The general practice computer records of incident cases were examined for the presence of "baseline" comorbidities, which were determined a priori as being related to outcome: diabetes (Read code C10 and below), peripheral vascular disease (Read code G73 and below), chronic kidney disease (14D, 14D1, 14V2, 1Z1,1Z10, 1Z11, 1Z1-4, 7B063, 7L1A-B, 8L50, G22, G220-z, G232-3, G701, G703, K05, K050, K0D, K07, K070-z, PD1, PD11-z, D215, ZV560, K0B, K0B1-6, K09, K090-1, K09z, K0C, K0C0-4, D3101, K03, K031-2, K06, K138z, P7690, TA020, ZV451), stroke (G65 to G654, G656 to G65zz, G61 below but not G617, G66 and below, G63y0-1, G6760, G6w, G6x, G64 and below), and hypertension (G2, G20 and below, G24 to G2z). We also examined the cohort for previous or subsequent recording of undefined chest pain (Read code 182 and below; not 1821) or receipt of an angina related prescription (antiplatelet, $\beta$ blocker, or nitrate). Each condition was recorded as a separate dichotomous variable. Similarly, the presence or absence of cardiovascular risk factors (current smoking (1372-1376, 137C-137D, 137G-137H, 137J, 137M, 137P-137R, 137V, 137X-137f, 137h) and being obese (defined as body mass index $>30$ ) before or after the date of the index episode of angina was ascertained by using the information closest to that date. We excluded those in whom smoking status and body mass index (BMI) were not recorded to avoid the effect of reporting bias in the analysis. The postcode of each patient was used to assign a deprivation status on a 10 point scale, which was then converted to fifths for analysis ( $1=$ most affluent to $5=$ most deprived) based on the Scottish index of multiple deprivation, which uses 37 indicators of poverty across seven domains (current income, employment, health, education, housing, geographical access, and crime).$^{9}$

\section{Follow-up}

Each patient was followed up to the event of interest, death, or for five years (1826 days) from the date of the index episode of angina, whichever came first. All outcome data were retrieved from the SMR01 secondary care records and GROS mortality records. The outcome measures were an SMR01 record for acute myocardial infarction (ICD-10 codes I21-I22), revascularisation by coronary artery bypass grafting (operation and procedures coding system 4 codes $\mathrm{K} 40-5)$, percutaneous transluminal coronary angioplasty with or without stents (K49, K501, K508-9), a GROS record of death from ischaemic heart disease (ICD-9 codes 410-4 (used by GROS for deaths before 2000) and ICD-10 codes (for year 2000 onwards) I20$25, \mathrm{I} 42, \mathrm{I} 46, \mathrm{I} 50)$, and death from any cause.

\section{Statistical analysis}

We used Student's $t$ tests and $\chi^{2}$ tests to compare continuous and categorical variables in different groups. Survival analysis was conducted to investigate the effect of different baseline characteristics on the time to the different outcomes. Cox proportional hazards models were initially fitted separately for each baseline characteristic to determine their individual effect. Full models were then fitted to calculate hazard ratios for 
each baseline variable with adjustment for other confounding variables. For outcomes of acute myocardial infarction, coronary artery bypass grafting, and percutaneous transluminal coronary angioplasty we censored patients at death or at five years after entry, whichever came first. For all cause mortality patients were censored at five years after entry, whereas for mortality from ischaemic heart disease, patients were censored at the time of other causes of death or at five years after entry. Survival analyses of time to acute myocardial infarction, percutaneous transluminal coronary angioplasty, coronary artery bypass grafting, death from ischaemic heart disease, and all cause mortality were adjusted for sex, age, deprivation, smoking, obesity, and comorbidity at baseline. We examined the effect on future risk of death of having an acute myocardial infarction or a cardiac procedure, or both, after the index diagnosis by including these variables as additional time varying covariates in an extension of the adjusted mortality analyses. We checked assumptions of proportional hazards using various diagnostic plots. Kaplan-Meier curves displayed the probability of survival over the study period among men and women of different ages. Analysis was conducted with SPSS version 15.0 (SPSS, Chicago, IL) and SAS (v9) software package (SAS Institute, Cary, NC).

\section{RESULTS}

Among the 40 practices, 6676 patients had angina pectoris recorded between 1 January 1998 and 31 December 2001. Checks of their records before the index episode found that 4609 of the patients had a previous general practice record of atrial fibrillation, heart failure, diagnosis of ischaemic heart disease, or a hospital admission related to ischaemic heart disease. A further 282 had incomplete data on smoking or BMI. Thus, 1785 patients were deemed to have had a first episode of angina as a first manifestation of ischaemic heart disease and had complete data. Of these, 326 patients (157 women) had a general practice record of undefined chest pain before the index episode of angina. Five hundred and eighty four patients (296 women) had chest pain recorded after their index angina episode; $482(82.5 \%)$ also had a subsequent general practice record of angina (246 women) and 538 (92.1\%) had a subsequent record of an ischaemic heart disease condition (273 women). Forty six patients had a record of unspecified chest pain but no specific coding for ischaemic heart disease after entry into the cohort. Of these, 33 received prescriptions for angina related drugs (nitrates, $\beta$ blockers, or antiplatelets), six $(0.3 \%$ of the cohort) died without any subsequent treatment for ischaemic heart disease during follow-up, and seven $(0.4 \%)$ who lived beyond five years were without any codes for ischaemic heart disease or prescribing data related to angina after the initial diagnosis.

Some patients had more than one angina Read code recorded. Nearly all codes had the descriptor of angina pectoris: G33 (angina pectoris: $\mathrm{n}=1355$ ), G33zz (angina pectoris: $\mathrm{n}=861$ ), G33z (angina pectoris: $\mathrm{n}=53$ ). Smaller numbers had G311 (preinfarction syndrome: $n=115$ ), G3300 (nocturnal angina: $n=1$ ), G331 (Prinzmetal's angina: n=2), G332 (coronary artery spasm: n=1), G33z1 (stenocardia: n=1), G33z3 (angina on effort: $\mathrm{n}=14$ ), G33z4 (ischaemic chest pain: $\mathrm{n}=3$ ), G33z6 (new onset angina: $\mathrm{n}=1$ ), and G33z7 (stable angina: $\mathrm{n}=1$ ). Although we did not include unstable angina in our entry criteria, a subsequent search found only one patient with this condition recorded simultaneously with a code of G33 (angina pectoris).

The cohort included 846 (47.4\%) women and 939 $(52.6 \%)$ men (table 1$)$. The mean age at cohort entry was 62.3 (SD 11.3). Women were significantly older than men (mean age at entry 63.6 (SD 11.3) $v 61.2$ (SD 11.2); $t=4.4 ; \mathrm{P}<0.001)$ and were more likely to have hypertension and be obese, while men were more likely to have had a previous stroke (table 1).

Within the five years' follow-up, $152(8.5 \%)$ patients underwent coronary artery bypass grafting, 108 (6.1\%) underwent percutaneous transluminal coronary angioplasty, $116(6.5 \%)$ had an acute myocardial infarction, $84(4.8 \%)$ died from ischaemic heart disease, and 175 $(9.8 \%)$ died from any cause. All of the events were more common in men than women. A fairly consistent pattern emerged of events occurring more often among individuals with a history of comorbidity, although many of the differences were not significant.

Hazard ratios adjusted for potential confounding factors indicated that the likelihood of having a coronary procedure remained significantly higher in men than in women even after we allowed for differences in the baseline characteristics (table 2). Older age was associated with a reduced likelihood of having a percutaneous transluminal coronary angioplasty. None of the other baseline characteristics was significantly associated with likelihood of receiving either cardiac procedure. In those patients who received the procedures, the median (interquartile range) times to coronary artery bypass grafting and percutaneous transluminal coronary angioplasty were 436.5 (201.0-836.5) days and 218.5 (78.5-508.0) days, respectively.

Male sex, older age, and smoking were associated with an increased likelihood of having an acute myocardial infarction (table 3). In those patients who

Table 1| Number (percentage) of women and men in cohort with history of comorbidity and cardiovascular risk factors at baseline

\begin{tabular}{lcccc} 
& $\begin{array}{c}\text { Total } \\
(\mathrm{n}=1785)\end{array}$ & $\begin{array}{c}\text { Women } \\
(\mathrm{n}=846)\end{array}$ & $\begin{array}{c}\text { Men } \\
(\mathrm{n}=939)\end{array}$ & P value \\
Comorbidity: & & & & \\
\hline Diabetes & $185(10.4)$ & $78(9.2)$ & $107(11.4)$ & 0.132 \\
\hline Previous stroke & $119(6.7)$ & $40(4.7)$ & $79(8.4)$ & 0.002 \\
\hline PVD & $109(6.1)$ & $44(5.2)$ & $65(6.9)$ & 0.129 \\
\hline Hypertension & $592(33.2)$ & $324(38.3)$ & $268(28.5)$ & $<0.001$ \\
\hline CKD & $14(0.8)$ & $7(0.8)$ & $7(0.7)$ & 0.845 \\
\hline Current smoker & $618(34.6)$ & $275(32.5)$ & $343(36.5)$ & 0.074 \\
\hline Obese & $338(18.9)$ & $179(21.2)$ & $159(16.9)$ & 0.023
\end{tabular}

$\mathrm{PVD}=$ peripheral vascular disease; $\mathrm{CKD}=$ chronic kidney disease. 
Table 2 | Proportions and unadjusted and adjusted hazard ratios for coronary procedures by baseline characteristics

\begin{tabular}{|c|c|c|c|c|c|c|}
\hline \multirow[b]{3}{*}{ Baseline characteristic } & \multicolumn{3}{|c|}{ Coronary artery bypass grafting } & \multicolumn{3}{|c|}{ Percutaneous transluminal coronary angioplasty } \\
\hline & \multirow[b]{2}{*}{ No (\%) } & \multicolumn{2}{|c|}{ Hazard ratio $(95 \% \mathrm{Cl})$} & \multirow[b]{2}{*}{ No (\%) } & \multicolumn{2}{|c|}{ Hazard ratio $(95 \% \mathrm{Cl})$} \\
\hline & & Unadjusted & Adjusted & & Unadjusted & Adjusted \\
\hline Men $(v$ women $\dagger)$ & $117(12.5)$ & $3.23(2.22 \text { to } 4.71)^{\star \star \star}$ & $3.11(2.12 \text { to } 4.56)^{\star \star \star}$ & $71(7.6)$ & $1.80(1.21 \text { to } 2.67)^{\star \star}$ & $1.58(1.05 \text { to } 2.36)^{*}$ \\
\hline Increasing age (per year) & $62(54-67) \ddagger$ & $0.99(0.97 \text { to } 0.999)^{\star}$ & $0.99(0.97$ to 1.00$)$ & $60(50-66) \ddagger$ & $0.97(0.95 \text { to } 0.98)^{\star \star *}$ & $0.97(0.95 \text { to } 0.98)^{\star \star \star}$ \\
\hline \multicolumn{7}{|l|}{ Deprivation fifth ( $v 1 \mathrm{st}) \S$ : } \\
\hline $2 n d$ & $29(8.7)$ & $0.75(0.44$ to 1.29$)$ & $0.86(0.50$ to 1.47$)$ & $19(5.7)$ & $0.74(0.38$ to 1.43$)$ & $0.79(0.41$ to 1.55$)$ \\
\hline $3 \mathrm{rd}$ & $38(8.6)$ & $0.75(0.45$ to 1.25$)$ & $0.82(0.49$ to 1.38$)$ & $28(6.4)$ & $0.82(0.45$ to 1.52$)$ & $0.86(0.47$ to 1.60$)$ \\
\hline 4th & $34(8.3)$ & $0.73(0.43$ to 1.23$)$ & $0.75(0.44$ to 1.27$)$ & $27(6.6)$ & $0.86(0.46$ to 1.60$)$ & $0.80(0.43$ to 1.50$)$ \\
\hline 5th & 27 (6.9) & $0.60(0.35$ to 1.04$)$ & $0.66(0.38$ to 1.16$)$ & $18(4.6)$ & $0.60(0.31$ to 1.18$)$ & $0.56(0.28$ to 1.11$)$ \\
\hline \multicolumn{7}{|l|}{ Comorbidity (yes $v$ no): } \\
\hline Diabetes & $21(11.4)$ & $1.39(0.88$ to 2.20$)$ & 1.28 (0.79 to 2.06$)$ & $15(8.1)$ & $1.41(0.82$ to 2.43$)$ & 1.48 (0.84 to 2.59$)$ \\
\hline CKD & $2(14.3)$ & $1.70(0.42$ to 6.85$)$ & $1.58(0.39$ to 6.43$)$ & $1(7.1)$ & $1.16(0.16$ to 8.34$)$ & 1.19 (0.17 to 8.59$)$ \\
\hline Stroke & $10(8.4)$ & 1.04 (0.55 to 1.98$)$ & $0.86(0.45$ to 1.66$)$ & $7(5.9)$ & $1.00(0.46$ to 2.15$)$ & $1.11(0.51$ to 2.43$)$ \\
\hline PVD & $13(11.9)$ & $1.46(0.82$ to 2.57$)$ & 1.38 (0.77 to 2.49 ) & $6(5.5)$ & 0.90 (0.40 to 2.05$)$ & 0.99 (0.43 to 2.29) \\
\hline Hypertension & $56(9.5)$ & $1.20(0.86$ to 1.66$)$ & $1.40(0.99$ to 1.98$)$ & $31(5.2)$ & 0.81 (0.53 to 1.23$)$ & $0.92(0.60$ to 1.42$)$ \\
\hline Smoker (yes v no) & $57(9.2)$ & 1.15 (0.83 to 1.60$)$ & $1.12(0.79$ to 1.60$)$ & $43(7.0)$ & 1.28 (0.87 to 1.88$)$ & $1.07(0.70$ to 1.61$)$ \\
\hline Obese (yes $v$ no) & $22(6.5)$ & $0.73(0.47$ to 1.15$)$ & 0.71 (0.45 to 1.13$)$ & $18(5.3)$ & 0.87 (0.52 to 1.44$)$ & $0.76(0.45$ to 1.28$)$ \\
\hline
\end{tabular}

$\mathrm{CKD}=$ chronic kidney disease; $\mathrm{PVD}=$ peripheral vascular disease.

${ }^{\star} \mathrm{P}<0.05 ;{ }^{* *} \mathrm{P}<0.01 ;{ }^{* * *} \mathrm{P}<0.001$.

$\dagger 35$ (4.1\%) women had coronary artery bypass grafting and 37 (4.4\%) had percutaneous transluminal coronary angioplasty.

$\ddagger$ Median (interquartile range) ages of outcome

§In first fifth of deprivation $24(11.4 \%)$ had coronary artery bypass grafting and 16 (7.6\%) had percutaneous transluminal coronary angioplasty.

experienced an acute myocardial infarction during the study period, the median (interquartile range) time to event was 225.5 (7.0-750.0) days.

Male sex, older age, smoking and obesity were each associated with a significant increased risk of death from ischaemic heart disease or any cause (table 4). The figure shows Kaplan-Meier curves for all cause mortality in men and women stratified by age $(<65$, $65-74, \geq 75)$. After adjustment for baseline characteristics, a history of chronic kidney disease before the

Table 3 Proportions and unadjusted and adjusted hazard ratios for acute myocardial infarction by baseline characteristics

\begin{tabular}{|c|c|c|c|}
\hline \multirow[b]{2}{*}{ Baseline characteristic } & \multirow[b]{2}{*}{ No (\%) } & \multicolumn{2}{|c|}{ Hazard ratio $(95 \% \mathrm{Cl})$} \\
\hline & & Unadjusted & Adjusted \\
\hline Men ( $v$ women $\dagger$ ) & $77(8.2)$ & $1.85(1.26 \text { to } 2.72)^{\star \star}$ & 2.01 (1.35 to 2.97$)^{\star \star \star}$ \\
\hline Increasing age (per year) & $66(57-73) \ddagger$ & $1.02(1.01 \text { to } 1.04)^{\star \star}$ & $1.04(1.02 \text { to } 1.06)^{\star \star \star}$ \\
\hline \multicolumn{4}{|l|}{ Deprivation fifth $(v 1 \mathrm{st}) \S:$} \\
\hline 2 nd & $25(7.5)$ & 1.30 (0.65 to 2.58$)$ & 1.25 (0.63 to 2.49$)$ \\
\hline $3 r d$ & $34(7.7)$ & 1.36 (0.70 to 2.63$)$ & $1.35(0.70$ to 2.62$)$ \\
\hline 4th & $15(3.7)$ & $0.63(0.30$ to 1.35$)$ & 0.61 (0.29 to 1.32$)$ \\
\hline 5 th & $30(7.7)$ & $1.36(0.70$ to 2.65$)$ & $1.29(0.65$ to 2.55$)$ \\
\hline \multicolumn{4}{|l|}{ Comorbidity (yes v no): } \\
\hline Diabetes & $13(7.0)$ & 1.08 (0.61 to 1.93$)$ & $1.06(0.59$ to 1.92$)$ \\
\hline CKD & $1(7.1)$ & 1.09 (0.15 to 7.79$)$ & 1.32 (0.18 to 9.59$)$ \\
\hline Stroke & $8(6.7)$ & 1.07 (0.52 to 2.19) & 0.91 (0.44 to 1.90$)$ \\
\hline PVD & $9(8.3)$ & 1.30 (0.66 to 2.56$)$ & 1.01 (0.50 to 2.01$)$ \\
\hline Hypertension & $36(6.1)$ & 0.90 (0.61 to 1.34$)$ & $0.92(0.61$ to 1.38$)$ \\
\hline Smoker (yes v no) & $51(8.3)$ & $1.52(1.05 \text { to } 2.19)^{\star}$ & $1.94(1.31 \text { to } 2.89)^{\star \star}$ \\
\hline Obese (yes $v$ no) & $25(7.4)$ & 1.20 (0.77 to 1.86$)$ & 1.45 (0.91 to 2.30$)$ \\
\hline
\end{tabular}

$\mathrm{CKD}=$ chronic kidney disease; $\mathrm{PVD}=$ peripheral vascular disease.

${ }^{*} \mathrm{P}<0.05 ;{ }^{* \star} \mathrm{P}<0.01 ;{ }^{* \star \star} \mathrm{P}<0.001$.

$\dagger 39$ (4.6\%) women had diagnosis of acute myocardial infarction.

$\ddagger$ Median (interquartile range) ages of outcome.

§In first fifth of deprivation $12(5.7 \%)$ patients had diagnosis of acute myocardial infarction. index episode was associated with an increased risk of death from ischaemic heart disease, and history of stroke with all cause mortality. Among those who died, the median (interquartile range) time to death from ischaemic heart disease was 842.5 (417.0-1179.0) days and to any death 771.0 (417.0-1193.0) days.

As an extension to the adjusted mortality models, we included cardiac procedures and acute myocardial infarction after the index diagnosis as time varying covariates. We found significant hazard ratios associating acute myocardial infarction after a diagnosis of angina with an increased likelihood of subsequent death from ischaemic heart disease $(8.84,95 \%$ confidence interval 5.31 to 14.71$)$ and all cause mortality $(4.23,2.78$ to $6.43)$. The hazard ratio associated with coronary artery bypass grafting after index diagnosis was 0.49 ( 0.25 to 1.95) for death from ischaemic heart disease and 0.58 ( 0.25 to 1.32 ) for all cause mortality. The corresponding figures for percutaneous transluminal coronary angioplasty after index diagnosis were $0.45 \quad(0.13$ to 1.52 ) and 0.55 (0.22 to 1.38 ), respectively.

To minimise the risk of reporting bias, we excluded from the incident angina cohort those with baseline data missing on smoking and BMI. While the sex profile of excluded patients was similar to that of included patients (51.3\% $v \quad 52.6 \%$ men and $48.7 \%$ v $47.4 \%$ women), those excluded were substantially older (mean age 73.8 (SD 12.6) v 62.3 (SD 11.3)). Inclusion of individuals with missing data, however, produced similar patterns of association to those presented.

\section{DISCUSSION}

Several baseline characteristics in people with a first diagnosis of angina are associated with subsequent risk of a number of cardiac outcomes. These 
Table $4 \mid$ Proportions and unadjusted and adjusted hazard ratios for mortality by baseline characteristics

\begin{tabular}{|c|c|c|c|c|c|c|}
\hline \multirow[b]{3}{*}{ Baseline characteristic } & \multicolumn{3}{|c|}{ Ischaemic heart disease mortality } & \multicolumn{3}{|c|}{ All cause mortality } \\
\hline & \multirow[b]{2}{*}{ No (\%) } & \multicolumn{2}{|c|}{ Hazard ratio $(95 \% \mathrm{Cl})$} & \multirow[b]{2}{*}{ No (\%) } & \multicolumn{2}{|c|}{ Hazard ratio $(95 \% \mathrm{Cl})$} \\
\hline & & Unadjusted & Adjusted & & Unadjusted & Adjusted \\
\hline Men ( $v$ woment) & $62(6.6)$ & $2.40(1.50 \text { to } 3.85)^{\star \star \star}$ & $2.80(1.73 \text { to } 4.53)^{\star \star \star}$ & $110(11.7)$ & $1.57(1.16 \text { to } 2.14)^{\star \star}$ & $1.82(1.33 \text { to } 2.49)^{\star \star \star}$ \\
\hline Increasing age (per year) & $71.5(62-77) \ddagger$ & $1.07(1.04 \text { to } 1.09)^{\star \star \star}$ & $1.09(1.06 \text { to } 1.11)^{\star \star \star}$ & $71(61-77) \ddagger$ & $1.07(1.05 \text { to } 1.09)^{\star \star \star}$ & $1.09(1.07 \text { to } 1.11)^{\star \star \star}$ \\
\hline \multicolumn{7}{|l|}{ Deprivation fifth ( $v$ 1st)§: } \\
\hline $2 n d$ & $15(4.5)$ & 1.57 (0.61 to 4.05$)$ & $1.41(0.54$ to 3.66$)$ & $33(9.9)$ & 1.09 (0.62 to 1.92$)$ & $0.97(0.55$ to 1.71$)$ \\
\hline $3 r d$ & $19(4.3)$ & $1.51(0.60$ to 3.78$)$ & $1.50(0.60$ to 3.78$)$ & $40(9.1)$ & $1.00(0.58$ to 1.73$)$ & $0.96(0.56$ to 1.67$)$ \\
\hline 4th & $25(6.1)$ & $2.17(0.89$ to 5.28$)$ & $2.22(0.91$ to 5.45$)$ & $44(10.8)$ & $1.20(0.70$ to 2.06$)$ & $1.22(0.71$ to 2.10$)$ \\
\hline 5th & $21(5.4)$ & $1.90(0.77$ to 4.72$)$ & $1.91(0.76$ to 4.79$)$ & $39(10.0)$ & $1.12(0.65$ to 1.93$)$ & $1.08(0.62$ to 1.89$)$ \\
\hline \multicolumn{7}{|l|}{ Comorbidity (yes $v$ no): } \\
\hline Diabetes & $10(5.4)$ & 1.13 (0.59 to 2.19$)$ & 0.97 (0.49 to 1.91$)$ & $19(10.3)$ & 1.05 (0.65 to 1.69$)$ & $0.92(0.57$ to 1.50$)$ \\
\hline CKD & $3(21.4)$ & $4.81(1.52 \text { to } 15.21)^{\star \star}$ & $5.72(1.74 \text { to } 18.79)^{\star \star}$ & $3(21.4)$ & $2.32(0.74$ to 7.28$)$ & 2.82 (0.88 to 8.98$)$ \\
\hline Stroke & $12(10.1)$ & $2.43(1.32 \text { to } 4.48)^{\star \star}$ & 1.80 (0.96 to 3.38) & $23(19.3)$ & $2.28(1.47 \text { to } 3.53)^{\star \star \star \star}$ & $1.78(1.13 \text { to } 2.80)^{\star}$ \\
\hline PVD & $8(7.3)$ & $1.59(0.77$ to 3.30$)$ & 0.85 (0.40 to 1.79$)$ & $17(15.6)$ & $1.67(1.02 \text { to } 2.76)^{\star}$ & 1.01 (0.60 to 1.68$)$ \\
\hline Hypertension & $30(5.1)$ & $1.09(0.70$ to 1.70$)$ & 1.01 (0.63 to 1.61$)$ & $59(10.0)$ & $1.03(0.76$ to 1.41$)$ & 0.91 (0.66 to 1.27$)$ \\
\hline Smoker (yes v no) & $34(5.5)$ & $1.26(0.82$ to 1.94$)$ & $2.12(1.32 \text { to } 3.39)^{\star \star}$ & $67(10.8)$ & 1.19 (0.88 to 1.62$)$ & $2.11(1.52 \text { to } 2.95)^{\star \star \star}$ \\
\hline Obese (yes $v$ no) & $19(5.6)$ & 1.24 (0.75 to 2.07$)$ & $2.01(1.17 \text { to } 3.45)^{\star}$ & $41(12.1)$ & 1.34 (0.95 to 1.90$)$ & $2.20(1.52 \text { to } 3.19)^{\star \star \star}$ \\
\hline
\end{tabular}

characteristics include (depending on outcome examined) male sex, age, smoking, obesity, and previous stroke or chronic kidney disease. An acute myocardial infarction after the index episode of angina greatly increased the risk of subsequent death. Although there was a suggestion that both coronary artery bypass grafting and percutaneous transluminal coronary angioplasty after a diagnosis of angina might reduce the subsequent risk of death from ischaemic heart disease or all cause mortality, none of the risk estimates reached significance.

Results in the context of other recent angina cohorts

Within the spectrum of ischaemic heart disease, angina in primary care has received insufficient attention. ${ }^{67}$ Previous studies of prognostic risk after a diagnosis of angina have had several important limitations: use of selected populations, often from secondary or tertiary care; lack of longitudinal data from an early stage of disease; different criteria used to define, diagnose, or report angina; and incomplete information about a range of outcomes, such as acute myocardial infarction, coronary artery bypass grafting, percutaneous transluminal coronary angioplasty, or mortality. Many studies have examined prevalent groups of individuals, often established through a cross sectional study that identifies everyone with angina in a given population at a particular point in time, rather than incident groups established by the identification of new cases over a period of time. Prevalent cohorts will include individuals at different stages of disease, including a proportion of individuals who have had angina for some time. Studies of such cohorts might underestimate survival after a first diagnosis of angina.

\section{Strengths and implications}

A major strength of our study was the use of a large incident cohort of patients identified in primary care and thus not prone to the selection biases that can occur through the referral process. Other strengths were the relatively long follow-up, the availability of

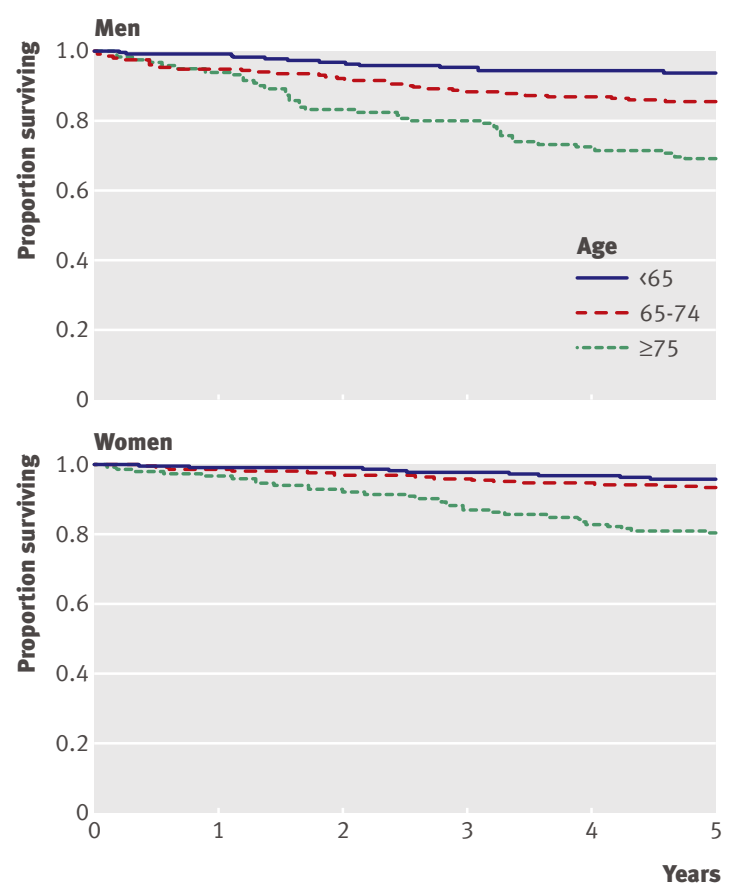

Comparison of survival from all cause mortality for men and women by age group. Difference in survival between age groups was highly significant for both men and women $(\mathrm{P}<0.001)$ 
data on several characteristics of individuals before the index diagnosis, and the novel database linkage, which allowed the use of data recorded in secondary as well as primary care and data on cause of death from the general register office for Scotland. The use of outcome data from secondary care and the general register office allowed follow-up even when individuals left the practice where the index diagnosis was recorded. The case finding method used seems robust: of the patients included in the cohort because of a first record of angina, fewer than $1 \%$ had no subsequent record of angina, another ischaemic heart disease diagnosis, or treatment related to angina.

In comparison with a cohort of patients with angina identified from secondary care cardiology clinics for the large Euro Heart cohort, ${ }^{11}$ our cohort was slightly older $(62.3 v 61.0)$ and had proportionally fewer men $(52.6 \%$ v $58.0 \%)$. Our comorbidity profile was also different (for example, $33 \%$ in our study had hypertension and $10 \%$ had diabetes compared with $62 \%$ and $18 \%$, respectively, in the Euro Heart study). Another large global cohort of patients with stable angina from a cardiac clinic (the ACTION trial), which has subsequently been used to calculate an angina risk score, had a high proportion of men $(79.4 \%) .{ }^{12}$ These differences emphasise the need to be cautious when extrapolating findings from secondary to primary care, for instance when developing risk scores or guidelines.

We identified strong significant associations between male sex and subsequent acute myocardial infarction, death from ischaemic heart disease, and all cause mortality. Male sex was not identified as a significant predictor of acute myocardial infarction or death in either the ACTION or Euro Heart secondary care populations. ${ }^{112}$ The Renfrew-Paisley population based study also found that, compared with women, men had a higher likelihood of morbidity and mortality related to ischaemic heart disease. ${ }^{4}$

In our study smoking was significantly associated with an increased risk of subsequent acute myocardial infarction, death from ischaemic heart disease, and all cause mortality, supporting the findings derived from the ACTION trial cohort. We also found a significant association between obesity and mortality but not between obesity and subsequent acute myocardial infarction. Obesity was not included as a risk factor in the ACTION or Euro Heart studies. In line with the ACTION cohort, we identified an association between stroke and all cause death. The association in our study between chronic kidney disease and death from ischaemic heart disease in patients with angina was based on only three deaths, using Read codes for diagnoses of chronic kidney disease rather than calculations from estimated glomerular filtration rates. Nevertheless it is in line with findings from a recent Irish primary care cohort of people with ischaemic heart disease. ${ }^{13}$

We found that male sex was associated with an increased likelihood of receiving either coronary artery bypass grafting or percutaneous transluminal coronary angioplasty after index diagnosis. Other studies have shown sex based differences in service provision for cardiac patients. ${ }^{1415}$ The different sex profile of our primary care cohort compared with the secondary care based ACTION and Euro Heart populations might also indicate that more men than women diagnosed with angina are referred to secondary care, resulting in women being more likely to be managed solely in primary care.

A clinical implication highlighted by our study was the importance of preventing a subsequent acute myocardial infarction in patients diagnosed with angina. When included in the mortality models as a time varying covariate, acute myocardial infarction was associated with a large hazard ratio for both death from ischaemic heart disease and all cause mortality. These results suggest that appropriate control of risk factors and optimal use of preventive medical treatments should be aggressively pursued in patients with angina.

It is interesting that in this incident cohort of people with a first diagnosis of angina derived from primary care, neither coronary artery bypass grafting nor percutaneous transluminal coronary angioplasty was associated with significantly improved survival. It must be borne in mind that the findings relating to these interventions were based on a relatively small amount of data and thus might have lacked statistical power. In addition, the observational results might have been affected by unmeasured confounding. Yet, current evidence suggests these interventions do not confer the same survival benefits for all patients with ischaemic heart disease. ${ }^{16-20}$ Much of the literature is comparatively old and considered populations that were younger than those in our primary care cohort, predominantly men, and included patients with previous acute myocardial infarction as well as those with angina alone. Meta-analyses suggest that coronary artery bypass grafting principally benefits those with more severe ischaemic heart disease, two or three vessel disease, and left main artery disease, with no significant survival benefit in those with one or two vessel disease or low risk profile. ${ }^{171920}$ A more recent study has suggested that in older patients with angina, optimal medical treatment confers benefits similar to coronary artery bypass grafting. ${ }^{18}$ While the benefit associated with percutaneous transluminal coronary angioplasty in patients with acute coronary syndromes is established, its value in patients without these problems is less certain. ${ }^{16}$ Our results relating to percutaneous transluminal coronary angioplasty are in line with those from the recent COURAGE trial, which reported no significant difference in mortality or subsequent acute myocardial infarction when percutaneous transluminal coronary angioplasty plus optimal medical treatment was compared with optimal medical treatment alone among 2287 people with stable coronary artery disease $(78 \%$ of whom had angina at baseline) during a median follow-up of 4 . 6 years. ${ }^{21} \mathrm{~A}$ UK historical cohort study found that in contemporary routine clinical practice survival from death is similar after either coronary artery bypass grafting or percutaneous revascularisation. ${ }^{22} \mathrm{~A}$ recent Cochrane review of percutaneous transluminal 
coronary angioplasty with stents compared with coronary artery bypass grafting found no significant difference for subsequent acute myocardial infarction or mortality between the interventions in patients with stable angina or acute coronary syndromes.$^{23}$ Research has highlighted the need for further prognostic research in representative, real world populations of people with angina; such research might identify subgroups that benefit most from particular inter ventions. ${ }^{2324}$ Experimental studies such as large scale randomised clinical trials with prolonged follow-up might establish the effectiveness of such strategies while avoiding confounding issues.

\section{Study limitations}

Our study has several limitations. We studied only individuals who had a recorded diagnosis of angina on their general practice records. We are therefore unable to say anything about the prognosis of individuals with angina whose condition remains undiagnosed in the community. ${ }^{25}$ Others have already shown that women with previously unrecorded angina have an increased risk of death compared with those without such a history. ${ }^{26}$ We did not have any details of the criteria used by the general practitioners when recording an episode of angina or of any investigations used to make the diagnosis. It is possible that different criteria were used for different groups within the population, although the strong relation between diagnosis of angina, baseline characteristics, and risk of cardiac outcomes provides face validity for the index diagnosis. The introduction of the quality and outcomes framework for general practice in the UK in 2004 has resulted in increased referral of patients presenting with angina for diagnostic tests such as angiography. ${ }^{27}$ This will provide new opportunities to determine whether estimates of prognosis change with certainty of diagnosis, although it will be several more years before such work can be undertaken with

\section{WHAT IS ALREADY KNOWN ON THIS TOPIC}

The findings of prognostic studies of angina in secondary or tertiary care populations might not be transferable to primary care, and primary care populations have been insufficiently researched

In trial populations, the value of percutaneous transluminal coronary angioplasty in people with angina alone is uncertain

\section{WHAT THIS PAPER ADDS}

In patients with angina in primary care there is a significant association between male sex and subsequent acute myocardial infarction, death related to heart disease, or death from any cause

Prevention of subsequent acute myocardial infarction is important in patients diagnosed with angina to avoid a significantly increased risk of death

Neither coronary artery bypass grafting nor percutaneous transluminal coronary angioplasty was associated with a significantly reduced five year risk of death among patients with angina.

Linked primary and secondary care clinical datasets provide an important opportunity to conduct studies of prognosis quickly and cost effectively reasonable statistical precision. Although we were able to control for several important factors recorded at baseline, we did not control for treatments after diagnosis because data were not available about contraindications, severity of illness, and patients' preferences or adherence to treatments, all of which contribute to prescribing patterns and prognostic risk. Residual confounding, therefore, could explain some of our findings. We have already shown important differences between groups in the management of angina. For example, we have found a greater use of prophylactic treatments in younger people with angina, ${ }^{14}$ which might explain our finding here of a decreased risk of invasive cardiac procedures and increased risk of acute myocardial infarction and mortality with age. On the other hand, our previous finding that men are more likely than women to be given active treatment for their angina ${ }^{14}$ would not explain the greater risk of all cardiac outcomes among men in this study, unless use of different treatments was also associated with severity of disease. It is possible that practices that contribute data to clinical databases, such as the one used in this study, provide a different level of care from those that do not. If so, this could have important implications for the generalisability of our results. Finally, as with all studies in which multiple comparisons are made, some significant findings might have occurred by chance.

\section{Conclusions}

There are important differences in outcome with angina among certain subgroups. Men have a significantly increased likelihood of revascularisation, acute myocardial infarction, death from ischaemic heart disease, and all cause mortality.

Linked clinical datasets, such as the one described, provide important opportunities to study prognosis after an event quickly and cost effectively. Ideally, future studies of prognosis after a first episode of angina should focus on primary care; include patients who have been phenotyped after diagnostic tests such as coronary angiography; be able to look at the effects of different interventions (such as angioplasty without stenting, or with conventional stents or drug eluting stents, and medical treatments); allow for the frequency and severity of angina symptoms and changes in treatments and risk factor profiles over time.

We thank Terry Therneau and Jan Offord from the Mayo Clinic for the use of their SAS macros to create diagnostic plots for survival analysis assumption testing.

Contributors: BSB conceived and contributed to the design of the study, conducted the analyses, and drafted and finished the paper. CRS prepared the database and contributed to the design and conduct of the study and the writing of the paper. DJMCL conducted statistical analyses and contributed to writing the paper. AWM and PCH contributed to and oversaw the design and conduct of the study and contributed to the writing of the paper. BSB is guarantor.

Funding: This research received no specific grant from any funding agency in the public, commercial, or not-for-profit sectors.

Competing interests: None declared

Ethical approval: Use of the anonymous linked database for this research was approved by the privacy and advisory committee for the information services division and its Caldicott guardian. 
1 Sproston K, Primatesta P. Health survey for England 2003. Vol 1. Cardiovascular disease. London: Department of Health, 2003.

2 Bromley C, Sproston K, Shelton N. The Scottish health survey 2003. Edinburgh: Scottish Executive, 2005.

3 Mant J, McManus RJ, Hare R. Applicability to primary care of national clinical guidelines on blood pressure lowering for people with stroke: cross sectional study. BMJ 2006;332:635-7.

4 Murphy NF, Stewart S, Hart CL, Maclntyre K, Hole D, McMurray JJV. A population study of the long-term consequences of Rose angina: 20 year follow-up of the Renfrew-Paisley study. Heart 2006;92:1739-46.

5 Buckley B, Murphy AW. Do patients with angina alone have a more benign prognosis than patients with a history of acute myocardial infarction, revascularisation or both? Findings from a community cohort study. Heart 2008;95:461-7.

6 Jones M, Rait G, Falconer J, Feder G. Systematic review: prognosis of angina in primary care. Fam Pract 2006;23:520-8.

7 Timmis AD, Feder G, Hemmingway $H$. Prognosis of stable angina pectoris: why we need larger population studies with higher endpoint resolution. Heart 2006;93;786-91.

8 ISD Scotland. General practice-practice team information (PTI). 2009. www.isdscotland.org/pti.

9 Scottish Government. Scottish index of multiple deprivation. www. scotland.gov.uk/Topics/Statistics/SIMD/Overview.

10 McAlister FA, Murphy NF, Simpson CR, Stewart S, McIntyre K, Kirkpatrick M, et al. The influence of socioeconomic deprivation on the primary care burden and treatment of heart failure in Scotland. BMJ 2004;328:1110-2.

11 Daly CA, DeStavola B, Lopez Sendon JL, Tavazzi L, Boersma E, Clemens F, et al. Predicting prognosis in stable angina: results from the Euro heart survey of stable angina: propsective observational study. BMJ 2006;332:262-7.

12 Clayton TC, Lubsen J, Pocock SJ, Voko Z, Kirwan BA, Fox KAA, et al. Risk score for predicting death, myocardial infarction, and stroke in patients with stable angina, based on a large randomised trial cohort of patients. BMJ 2005;331:869-73.

13 Glynn L, Buckley B, Reddan D, Newell J, Hinde J, Dinneen SF, et al. Multimorbidity and risk among patients with established cardiovascular disease: a cohort study. Br J Gen Pract 2008;58:488-94.

14 Murphy NF, Simpson CR, MacIntyre K, McAlister FA, Chalmers J, McMurray JJV. Prevalence, incidence, primary care burden and medical treatment of angina in Scotland: age, sex and socioeconomic disparities: a population-based study. Heart 2006;92:1047-54.

15 Shaw M, Maxwell R, Rees K, Ho D, Oliver S, Ben-Shlomo Y, et al. Gender and age inequity in the provision of coronary revascularisation in England in the 1990s: is it getting better? Soc Sci Med 2004;59:2499-507.

16 Boden WE, O'Rourke RA, Teo KK, Hartigan PM, Maron DJ, Kostuk W], et al. Optimal medical therapy with or without PCI for stable coronary disease. N Engl J Med 2007;356:1503-16.

17 Charanjit SR, Raco DL, BJ. G, Yusuf S. Indications for coronary arten bypass surgery and percutaneous coronary intervention in chronic stable angina. Circulation 2003;108:2439-45.

18 Pfisterer M, Buser P, Osswald S, Allemann U, Amann W, Angehrn W, et al. Outcome of elderly patients with chronic symptomatic coronary artery disease with an invasive vs optimized medical treatment strategy: one-year results of the randomized TIME trial. JAMA 2003;289:1117-23.

19 Sculpher MJ, Petticrew M, Kelland JL, Elliott RA, Holdright DR, Buxton MJ. Resource allocation for chronic stable angina: a systematic review of the effectiveness, costs and cost-effectiveness of alternative interventions. Health Technol Assess 1998;2:1-176.

20 Yusuf S, Zucker D, Peduzzi P, Fisher LD, Takaro T, Kennedy JW, et al. Effect of coronary artery bypass graft surgery on survival: overview of 10-year results from randomised trials by the coronary artery bypass graft surgery trialists collaboration. Lancet 1994;344:563-70.

21 Weintraub WS, Spertus JA, Kolm P, Maron DJ, Zhang Z, Jurkovitz C, et al. Effect of $\mathrm{PCl}$ on quality of life in patients with stable coronary disease. N Engl J Med 2008;359:677-87

22 Blackledge HM, Squire IB. Improving long-term outcomes following coronary artery bypass graft or percutaneous coronary revascularisation: results from a large, population based cohort with first intervention 1995-2004. Heart 2009;95:304-11.

23 Bakhai A, Hill RA, Dundar Y, Dickson R, Walley T. Percutaneous transluminal coronary angioplasty with stents versus coronary artery bypass grafting for people with stable angina or acute coronary syndromes. Cochrane Database Syst Rev 2005;(1):CD004588.

24 Hemingway H. States, rates and traits: prognosis research and chronic stable angina. Heart 2009;95:439-40.

25 Hemingway H, Shipley M, Britton A, Page M, MacFarlane P, Marmot M. Prognosis of angina with and without a diagnosis: 11 year follow up in the Whitehall II prospective cohort study. BMJ 2003;327:895.

26 Owen-Smith V, Hannaford PC, Elliott AM. Increased mortality among women with Rose angina who have not presented with ischaemic heart disease. Br J Gen Pract 2003;53:784-9.

27 McGovern MP, Boroujerdi MA, Taylor MW, Williams DJ, Hannaford PC, Lefevre KE, et al. The effect of the UK incentive-based contract on the management of patients with coronary heart disease in primary care. Fam Pract 2008;25:33-9.

Accepted: 11 March 2009 